\title{
Core Competencies of University Students and Nursing Competencies: Literature Review
}

\section{Jihyun Kim}

Teaching lecture of nursing management, Department of Nursing, Baekseok University, South Korea

\author{
Article Details \\ Article Type: Research Article \\ Received date: $21^{\text {st }}$ November, 2018 \\ Accepted date: $31^{\text {st }}$ January, 2019 \\ Published date: $5^{\text {th }}$ March, 2019
}

"Corresponding Author: Jihyun Kim, Department of Nursing, Teaching lecture of nursing management, Baekseok University, Chohyunggwan Office No.724, 76 Moonamro, South Korea. E-mail: jhkimrn@bu.ac.kr

Citation: Kim J (2019) Core Competencies of University Students and Nursing Competencies : Literature Review. J Comp Nurs Res Care 4: 136. doi: https://doi.org/10.33790/jenrc1100136.

Copyright: $(02019$, This is an open-access article distributed under the terms of the Creative Commons Attribution License 4.0, which permits unrestricted use, distribution, and reproduction in any medium, provided the original author and source are credited.

\begin{abstract}
Background: core competency has begun to be emphasized as a key element for the university students preparing for the future as well as for the learning ability of leaner. Competence refers to the basic knowledge needed by the students and ability, power, skill, function, manner and attitude related to problem solving. Nursing competency is the ability of general nurses to perform nursing work regardless of field. It is a combination of knowledge, skills, and personal abilities to effectively perform professional work. The purpose of this research is that the basic concepts of competency, core competencies of university students and nursing competency literature review will be provided, and discuss the present status of Korea presented by reporting.

Review Result: K-CESA used in Korea as a core component of vocational competence refers to the knowledge, skills, and attitudes commonly required to perform a job successfully. Based on domestic and foreign literature, at a university of Korea has developed the BUCCA (Baekseok University Core Competency Assessment) consists of 6 areas, 17 outlines, and 69 items. Nursing students showed the higher level of servant leadership and spirit, calling, humanities than other major students. 7 nursing competencies are suggested by KABONE(Korea Accreditation board of Nursing Education) and a nursing curriculum developed based on that. A school of nursing in Korea develop 9 nursing competencies like as Integrated application of nursing knowledge, Critical thinking, Execute by selecting core basic nursing skills, Therapeutic communication skills, Coordination and Cooperation, Understand of professional standards and establishment of professional intuition, Understanding of healthcare policy and legal, ethical standards, Global nursing leadership, Nursing Research Ability.
\end{abstract}

Conclusion: A training course for nursing excellent nursing students should include both the core competencies needed by a college student and the nursing competencies to grow as a nurse. The two core competencies are closely related and this should be equally reflected in the curriculum and non subject programs. The development of innovative competency assessment methods is required in addition to the well-known CPE-based competency assessment.

\section{Introduction}

Recently, the term competency or core competency has begun to be emphasized as a key element for the university students preparing for the future as well as for the learning ability of leaner. Competence refers to the basic knowledge needed by the students and ability, power, skill, function, manner and attitude related to problem solving [1].

The concept of core competency in the context of inter-firm competition in business administration is a factor explaining the superior ability, that is, the competitive advantage, over the competition. Since then, the core competencies were discussed as a conceptual basis for the direction of development of the curriculum of the university. The concept of core competency in college education is becoming generalized as a core connection concept of linkage between education and labor market that responds to corporate needs.

In college education, it is an important issue at this time to cultivate competence as a complex ability element for future through learnercentered learning activities rather than lectures based on the injection of existing knowledge [2]. It is necessary to constantly identify the core competencies that college students need to reflect on the timely demands.

In addition, nursing competency is the ability of general nurses to perform nursing work regardless of field [3]. It is a combination of knowledge, skills, and personal abilities to effectively perform professional work. The learning experience of nursing college curriculum affects the competency that is used in clinical practice after graduation. Therefore, the designing of educational curriculum centered on nursing competency is required and there is a need to continually explore the nursing capacity reflecting the changes of the times.

In the main subject, the basic concepts of competency, core competencies of university students and nursing competency literature review will be provided, and the present status of Korea will be presented by reporting the development of core competency diagnostic tool for university students and nursing competency based curriculum development cases.

\section{Main Subject \\ Competency}

Competency is 1) precise and measurable action execution, 2) ability to use appropriate knowledge and skills in specific situations, 3) sufficient degree of ability and standard, 4) General qualities or conditions that characterize a person. Ultimately, competence can be seen as the ability that a student must have at the time of graduation. 
Until now the concept of competence has been designed and used mainly for companies, but after being linked with education, it was changed in the direction of acquiring theoretical and practical knowledge and to strengthen the actual work performance ability.

In college education, competency-based education with the concept of competency became important. It can be said that this is an education to evaluate students' achievement level based on the competence-related performance and by designing the curriculum through analysis of the actual role of modern society.

Therefore, competence as a cornerstone and guidance of educational planning, all elements of curriculum management such as selection and organization of education contents, teaching-learning methods and evaluation including setting of teaching-learning goals are progressed based on competency. Therefore, an efficient operation should be made by considering such facts [4].

For the competence centered curriculum, the achievement should be demonstrated after designing and operating the curriculum. Therefore, ongoing review of competencies can improve the quality of education and minimize fluctuations in educational outcomes [5].

\section{Core Competencies of University students}

Core competencies, in terms of employment and labor market, becomes the evaluation criteria to replace qualifications such as degrees and credits, and in terms of education and training institutions, it has the meaning as a criterion that defines the goals and contents of the curriculum [6].
The United States is pursuing college learning evaluation consisting of problem solving ability, analytical reasoning ability, critical thinking ability, and writing ability. Australia is conducting graduate skills assessment which includes communication/writing, problemsolving skills, interpersonal skills and teamwork, critical thinking skills, ethics and civic awareness, lifelong learning and information communication skills.

AHELO business of OECD has established and operates the higher education learning performance evaluation system complying with the International Academic Achievement Assessment (PISA). It includes general core competencies such as critical thinking, analytical reasoning, problem solving, and communication skills.It includes the field of major competence that measures knowledge and ability in the fields such as engineering and economics. It includes value-added measurement areas that measure the effects of college on learning outcomes, and a background factor area including information on country/school/student.

The Korea Collegiate Essential Skills Assessment (K-CESA) used in Korea as a core component of vocational competence refers to the knowledge, skills, and attitudes commonly required to perform a job successfully. K-CESA consists of 6 core competencies such as communication competency, global competency, utilization competency of resource information technology, comprehensive thinking ability, interpersonal capacity and self-management competency (Table-1). It is used to diagnose core competency level of college students [1,7]. Based on domestic and foreign

\begin{tabular}{|l|l|}
\hline Core competence category & Constituent factor \\
\hline Communication competency & Listening, discussing and adjusting, reading, writing, speaking \\
\hline Utilization competency of resource information technology & $\begin{array}{l}\text { Collection, analysis and utilization of resources, information and } \\
\text { technology }\end{array}$ \\
\hline Interpersonal competency & $\begin{array}{l}\text { Understanding on emotional ties, cooperation, mediation, } \\
\text { leadership and organization }\end{array}$ \\
\hline Global competency & $\begin{array}{l}\text { Foreign language ability, exposure on global environment, } \\
\text { multicultural understanding and acceptance capacity }\end{array}$ \\
\hline Comprehensive thinking ability & $\begin{array}{l}\text { Evaluative thinking, alternative thinking, reasoning, analytical } \\
\text { thinking }\end{array}$ \\
\hline Self-management competency & $\begin{array}{l}\text { Self-directed learning ability, goal-oriented planning and } \\
\text { execution ability, emotional self-regulation ability, professional } \\
\text { consciousness }\end{array}$ \\
\hline
\end{tabular}

Table 1. Core Competencies in K-CESA (Korea Collegiate Essential Skills Assessment)

literature, at a university of Korea has developed the Baekseok University Core Competency Assessment (BU-CCA) and been using it since 2016 [8].

When looking at the research related to university students' core competency, in the study of [6] analyzing the core competence and relevance of academic achievement showed that there is an increase in the achievement of core competencies as the grade increases [9]. However, it was reported that global competency score was low. It claimed that although international exchanges have increased, understanding and acceptance capacity of multicultural situations did not improve relatively.

In the study by [10], in the major subject, the need for science education was high at 2.91 [10]. Especially, it was reported that need for education was shown in the order of career development ability, information processing ability, interpersonal ability, communication ability, and problem solving ability. Especially, the Department of Engineering and Social Sciences had higher demand for creativity. Most students had high educational needs for all core competencies, and suggested that institutional coordination is required so that students can apply the class division by departments. Lee et al. [6] reported that analytical thinking, problem solving, and critical thinking of university students were related to academic achievements but claimed that creative thinking was not related to academic achievement [9].

When gathering the results of various studies, core competencies of university students were related to academic achievements as the grade increased, so there is a need to sufficiently reflect such results when designing a major curriculum.In addition, creative curriculum activities such as developing educational policies to enhance global competence for Korean university students and incorporating creative activities into the curriculum should be emphasized.

Kim, [11] has analyzed the differences in core competencies among nursing students and other major students [11]. Nursing students showed the higher level of servant leadership and spirit, calling, humanities than others. Main factors to affect major satisfaction field practice. To raise up the good point, it is need to consider strategies how to strengthen them in curriculum (Table-2). 


\begin{tabular}{|l|l|}
\hline Development procedure & Contents \\
\hline Core competency of B University & RAISE UP \\
\hline $\begin{array}{l}\text { A review of literature related to core competencies of college } \\
\text { students at home and abroad }\end{array}$ & $\begin{array}{l}\text { - Preliminary research and literature review } \\
\text { - System and status related to domestic and foreign university } \\
\text { student competency diagnosis }\end{array}$ \\
\hline $\begin{array}{l}\text { Development of preliminary question for Baekseok Core } \\
\text { Competency Diagnosis Tool (BU-CCA) }\end{array}$ & $\begin{array}{l}\text { - Secure content validity after gathering expert opinion and } \\
\text { item development. }\end{array}$ \\
\hline Reliability and validity analysis of preliminary diagnostic tool & $\begin{array}{l}\text { - Data collection using preliminary diagnostic tools } \\
\text { - Reliability and configuration validity, face validity analysis }\end{array}$ \\
\hline 69 items confirmed for Baekseok Core Competency Diagnosis \\
Tool (BU-CCA) \\
$\begin{array}{l}\text { Consists of } 6 \text { areas, 17 outlines, and } 69 \text { items } \\
\text {-Interpersonal skills has total of 13 items; Communication } \\
\text { (5 questions), Cooperation(4 questions), Respect and } \\
\text { consideration (4 questions), and Practical Service has a total of } \\
11 \text { items; Service leadership (4 items), Community citizenship } \\
\text { awareness (4 questions), Service Spirit (3 questions). } \\
- \text { The creative convergence ability includes Creative Thinking } \\
\text { (5 questions) and Problem solving ability(5 items), it includes } \\
\text { one inverse question. } \\
- \text { Site practical skills includes practical knowledge and skill } \\
\text { understanding (4 questions), collecting and usage of practical } \\
\text { information (3 items), and Resource management ability(4 } \\
\text { questions). } \\
- \text { Global communication skills includes Foreign language } \\
\text { ability (5 questions), Global culture acceptance (3 items), and } \\
\text { Local culture acceptance (4 questions) } \\
- \text { Literacy knowledge includes Christian ethics awareness (5 } \\
\text { questions), Calling consciousness (3 questions), and Humanistic } \\
\text { sensitivity(4 questions }\end{array}$ \\
\hline
\end{tabular}

Table 2. Development case of core competency diagnostic tools for a Korean university: BU-CCA development procedure and contents

\section{Nursing Competency}

Nursing competency is the ability of general nurses to perform nursing work regardless of field. Nursing core competencies is an important capability that is essential to carry out their duties and proving the professionality of the nurse [3]. Lenburg [12] has presented 8 kinds of nursing competencies and specific practical skills in his COPA model (Competency Outcome Practice Assessment Model) [12-13] (Table-3).

\begin{tabular}{|l|l|}
\hline Practical Skill Competency & Contents \\
\hline Assessment and Intervention Skills & $\begin{array}{l}\text { Review and data collection ability: physical condition, } \\
\text { treatment, nursing intervention }\end{array}$ \\
\hline Communication skills & Speaking, writing, computer skills \\
\hline Care and Relationship Skills & $\begin{array}{l}\text { Respect cultural backgrounds and build interrelationships } \\
\text { of patients and health care workers, patient advocacy and } \\
\text { patient-centered care }\end{array}$ \\
\hline Critical Thinking Skills & $\begin{array}{l}\text { Providing evidence-based nursing, integrating nursing theory } \\
\text { into clinical practice, problem solving, decision making and } \\
\text { scientific inquiry skills }\end{array}$ \\
\hline Education Skills & $\begin{array}{l}\text { Education for patients and health workers, health promotion } \\
\text { education consultation }\end{array}$ \\
\hline Lanagement Skills & $\begin{array}{l}\text { Nursing administrative organization management, } \\
\text { cooperation with health care workers, task assignment, } \\
\text { utilization of human / material resources, carry out activities } \\
\text { for nursing quality management }\end{array}$ \\
\hline Knowledge integration ability & $\begin{array}{l}\text { Cooperation, presenting vision, professional responsibility, } \\
\text { self development }\end{array}$ \\
\hline
\end{tabular}

Table 3. Core competencies in COPA model 
In Korea, based on domestic and foreign research results since 2012, has identified the core competencies of nurses commonly required for performing various duties at clinical sites 2-3 years after the graduation and there is movement to operate the curriculum reflecting this.
In Korea, according to the Medical Law, all nursing departments are required to receive accreditation and this is administered by the Korea Nursing Education and Research Institute. Table 4 is the core competency of nurses and its definition presented by the Korea Nursing Education Evaluation Institute [14].

\begin{tabular}{|l|l|}
\hline Core competencies & Contents \\
\hline $\begin{array}{l}\text { Cultural knowledge for providing full-time nursing care and } \\
\text { ability to integrate nursing skills }\end{array}$ & $\begin{array}{l}\text { Collecting the data necessary for troubleshooting, physical } \\
\text { examination, nursing skills and instrument operating ability } \\
\text { according to the change of the health functional aspect of the } \\
\text { subject }\end{array}$ \\
\hline $\begin{array}{l}\text { Ability to communicate and collaborate with specialist fields to } \\
\text { improve the health of the subject }\end{array}$ & $\begin{array}{l}\text { Ability to share accurate information with the subject through } \\
\text { verbal and nonverbal methods and ability to share information } \\
\text { with the healthcare team }\end{array}$ \\
\hline Critical thinking ability for nursing problem solving & $\begin{array}{l}\text { Ability to analyze and solve problems by reasonably exploring } \\
\text { the problems with intellectual curiosity }\end{array}$ \\
\hline $\begin{array}{l}\text { Ability to conduct research for the scientific development of } \\
\text { nursing practice }\end{array}$ & $\begin{array}{l}\text { Possible to respond to questions and requests considering the } \\
\text { individual situation of the subject, and ability to maximize the } \\
\text { subject's potential to maintain the best health }\end{array}$ \\
\hline Leadership to achieve nursing goals & $\begin{array}{l}\text { Ability to utilize and manage human, financial and physical } \\
\text { resources to achieve high quality health care results }\end{array}$ \\
\hline $\begin{array}{l}\text { Ability to recognize legal and ethical responsibility for nursing } \\
\text { professional development }\end{array}$ & $\begin{array}{l}\text { Ability to support and represent the subject by maintaining } \\
\text { interdisciplinary and interdisciplinary teamwork } \\
\text { conducting self-directed nursing practice within the ethical and } \\
\text { legal framework }\end{array}$ \\
\hline Ability to respond to changes in global health care policy & $\begin{array}{l}\text { Ability to apply to individual, family, and community care by } \\
\text { recognizing the changes in domestic and overseas health care } \\
\text { policy and by utilizing expertise and resources }\end{array}$ \\
\hline
\end{tabular}

Table 4. Core Competencies of Nurses(Korea Accreditation board of Nursing Education, 2012)

At a university in Korea, a competency-based curriculum was operated by identifying and reflecting the core competencies of nursing students into educational goals. A questionnaire was conducted on the core competencies of nurses targeting graduates and clinical nursing managers and a comprehensive analysis was made by reflecting the job analysis results and health care policy. The core competencies for nursing student education are shown in Table 5.

\begin{tabular}{|l|l|}
\hline Core Competencies & Reflected to Educational Goal \\
\hline Integrated application of nursing knowledge & $\begin{array}{l}\text { Apply nursing knowledge required for former nursing integrally } \\
\text { to practice }\end{array}$ \\
\hline Critical thinking & $\begin{array}{l}\text { Apply critical thinking based nursing process to solve nursing } \\
\text { problem }\end{array}$ \\
\hline Execute by selecting core basic nursing skills & $\begin{array}{l}\text { Select and execute core basic nursing care to solve the nursing } \\
\text { problem }\end{array}$ \\
\hline Therapeutic communication skills & $\begin{array}{l}\text { Apply therapeutic communication through verbal and } \\
\text { nonverbal interactions }\end{array}$ \\
\hline Coordination and Cooperation & $\begin{array}{l}\text { Coordinate and co-operate in-team work to resolve health } \\
\text { problems }\end{array}$ \\
\hline $\begin{array}{l}\text { Understand of professional standards and establishment of } \\
\text { professional intuition }\end{array}$ & $\begin{array}{l}\text { Establish nursing professional intuition and understand nursing } \\
\text { professional standards }\end{array}$ \\
\hline $\begin{array}{l}\text { Understanding of healthcare policy and legal, ethical } \\
\text { standards }\end{array}$ & $\begin{array}{l}\text { Understand legal and ethical standards of nursing and health } \\
\text { care policy and integrate them into nursing practice }\end{array}$ \\
\hline Global nursing leadership & $\begin{array}{l}\text { Demonstrate global nursing leadership based on a Christian } \\
\text { worldview }\end{array}$ \\
\hline Nursing Research Ability & Carry out nursing research based on scientific evidence \\
\hline
\end{tabular}

Table 5. A case of reflecting the core competency of nurses in the curriculum of nursing students 
When examining the study on the nursing competency and core competence targeting nursing students, a recent increase can be seen. Bac [15] has studied the structural equation modeling on core competencies of nursing students, where the satisfaction with major and clinical practice has an indirect effect on nursing core competencies, and the critical thinking tendency was reported to have shown a direct effect [15]. Therefore, to promote nursing core competencies, a satisfaction of major should be promoted through curriculum process development, comparison of core competencies and strengthening of education that improve critical thinking, and it is necessary to develop strategies for clinical practice education and practice guidance.

Kim [16] has conducted a descriptive study in order to investigate whether the learning experience of nursing college students affected the enhancement of core competencies using K-NSSE valuated by Bae [16-17]. Among the core competencies of the survey subjects, interpersonal skills were 3.96, creative convergence competencies were 3.95 , site practical skills were 3.68 , and global communication competencies were 3.49 showing that figures were above the middle. Among the learning experience factor, 'academic challenge' and 'learning with peers' were related to all core competencies and reported that academic challenge was the highest [16]. Therefore, to improve the core competency level of nursing college students, teaching methods that strengthens reflective integrated learning, higher-level learning, and learning strategies are needed by applying it into the curriculum process. New teaching and learning strategies that can inspire critical thinking by avoiding existing simple memorization-oriented nursing education should be developed and applied. There is also a need to continue to explore the curriculum and out-of-curriculum that can be done with colleagues.

Lerburg et al. [13] suggest that nursing students should raise their 8 competencies including communication skill, human relationships, management and knowledge integration in COPA model [13]. These competencies are very related with nursing field after school. So Strategies need to be developed in CPE in the simulation or other methods.

\section{Conclusion}

A training course for nursing excellent nursing students should include both the core competencies needed by a college student and the nursing competencies to grow as a nurse. The two core competencies are closely related and this should be equally reflected in the curriculum and co-curriculum programs. And periodically, it should be used to improve the curriculum by exploring the needs of students and clinical sites and by evaluating the achievement of competencies. In order to do so, the development of innovative competency assessment methods is required in addition to the wellknown CPE-based competency assessment.

Conflict of Interest: The author has no conflict of interest.

Acknowledgement: This artice was supported by a grant from Baekseok University

\section{Reference}

1. Jin MS (2013) 2012 K-CESA diagnosis support project KRIVET (Korea Research Institute for Vocational Education \& Training)

2. Caligiuri P, Santo DV (2001) Global competence: what is it, and can it be developed through global assignments? Human Res Plan 3: 27-35.

3. International Council of Nurses (2008) Nursing Care Continuum Framework and Competencies, ICN Regulation Series

4. Park Young, Kim A, Ja-Kyung K, Chung MS, Bang KS et al. (2013) An Identification Study on Core Nursing Competency. J Korean Acad Soc Nurs Edu 4: 663-674

5. Model TF, Bird JL (2010) Continuous curriculum review in a bachelor of nursing program: preventing curriculum drift and improving quality. J Nurs Edu 10: 592-595.
6. Lee JIK, Kim JH (2012) A study on the relationship between college students' essential skills and academic achievement. J Vocat Edu Res 31: 227-246.

7. Park IS, Jeon HN (2015) The effect of core competency on stress coping and problem solving ability of nursing students. Proceeding of the 4th K-CESA conference.

8. Kim J, Gum HJ, Lim MR, Yim SY, Shin SH, et al. (2017) Development of BU-CCA,(Baekseok Core Competency Assessment tool). Baekseok University Press

9. Kim HY, Lee SJ (2012) Diagnosis and direction of the competence-based educational model: Based on the courses and Effects. J Gen Edu 4: 11-40

10. Heojeong Y, Bang D (2015) Analysis of undergraduate students' educational needs for key competencies in curriculum of major subject and liberal arts. J Learner-Centered Curric Instr 15: 567584.

11. Jihyun Kim (2017) Difference in Core Competence and Major Satisfaction Factors among Nursing Students and Other Undergraduates. Proceeding of 2017 International conference on convergence technology

12. Lenburg C, Klein C, Abdur-Rahman V, Spencer T, Boyer S, et al. (2009) A Comprehensive Framework Designed to Promote Quality Care and Competence for Patient Safety. Nursing Education Perspectives 5: 312-317

13. Lenburg C, Abdur-Rahman V, Spencer T, Boyer S, Klein C et al. (2011) Implementing the COPA model in nursing education and practice settings: promoting competence, quality care, and patient safety. Nurs Edu Perspect 5: 290-296

14. Korea Accreditation board of Nursing Education (2012) Teaching workshop for performance-based curriculum management.

15. Bae DY (2016) Structural equation modeling on core competencies of nursing students on graduation time. Doctoral dissertation of Kyoungsang University, Korea.

16. Kim J (2018) Effects of Learning Experience on Core Competencies of Nursing Students.

17. Bae SH, Kang MS, Hong JI (2015) Validation of the National Survey of Student Engagement (NSSE) Model in the Korean Context. Asian J Edu 4: 77-104 